\title{
TEJER LA MEMORIA, TOMAR EL PODER
}

\author{
Zulma Palermo*
}

RESUMO: estas páginas se propõem a gerar uma reflexão sobre o "cânone ocidental" que rege os critérios de validação da produção artística. Para tanto, explora-se visualmentes alguns textos - em diferentes suportes - selecionados para esta finalidade, o que possibilida colocar em crise os critérios diferenciadores entre "arte" $e$ "artesanato" gerados pelo paradigma da modernidade ocidental. Busca-se demonstrar que tais categorias são consequência de um projeto hegemônico cujo poder se sustenta até nossos dias.

\section{PALAVRAS-CHAVE: arte, artesanato, diferença colonial, identidade}

Quisiera iniciar esta propuesta con un desafío, el que nos plantea la visualización de unas imágenes, para pensarlas desde nuestra concepción de lo que es estético, es decir, de aquellos productos simbólicos que el orden de la cultura occidental y moderna distingue como artísticos. La que vemos a nuestra izquierda es una obra de Tarsilia do Amaral, reconocida por el canon como una de las manifestaciones más logradas de la plástica brasilera "modernista". La de la derecha, una estatuilla en barro cocido, gestada por manos anónimas y cuyo destino final es la mirada de los visitantes de un museo provinciano de contenido étnico ${ }^{1}$.

\footnotetext{
* Profesora de la Universidad Nacional de Salta (UNSA - Argentina).

${ }^{1}$ Pertenece a la colección privada del Museo de Arte Etnico Pajcha, de la ciudad de Salta (Argentina).
} 


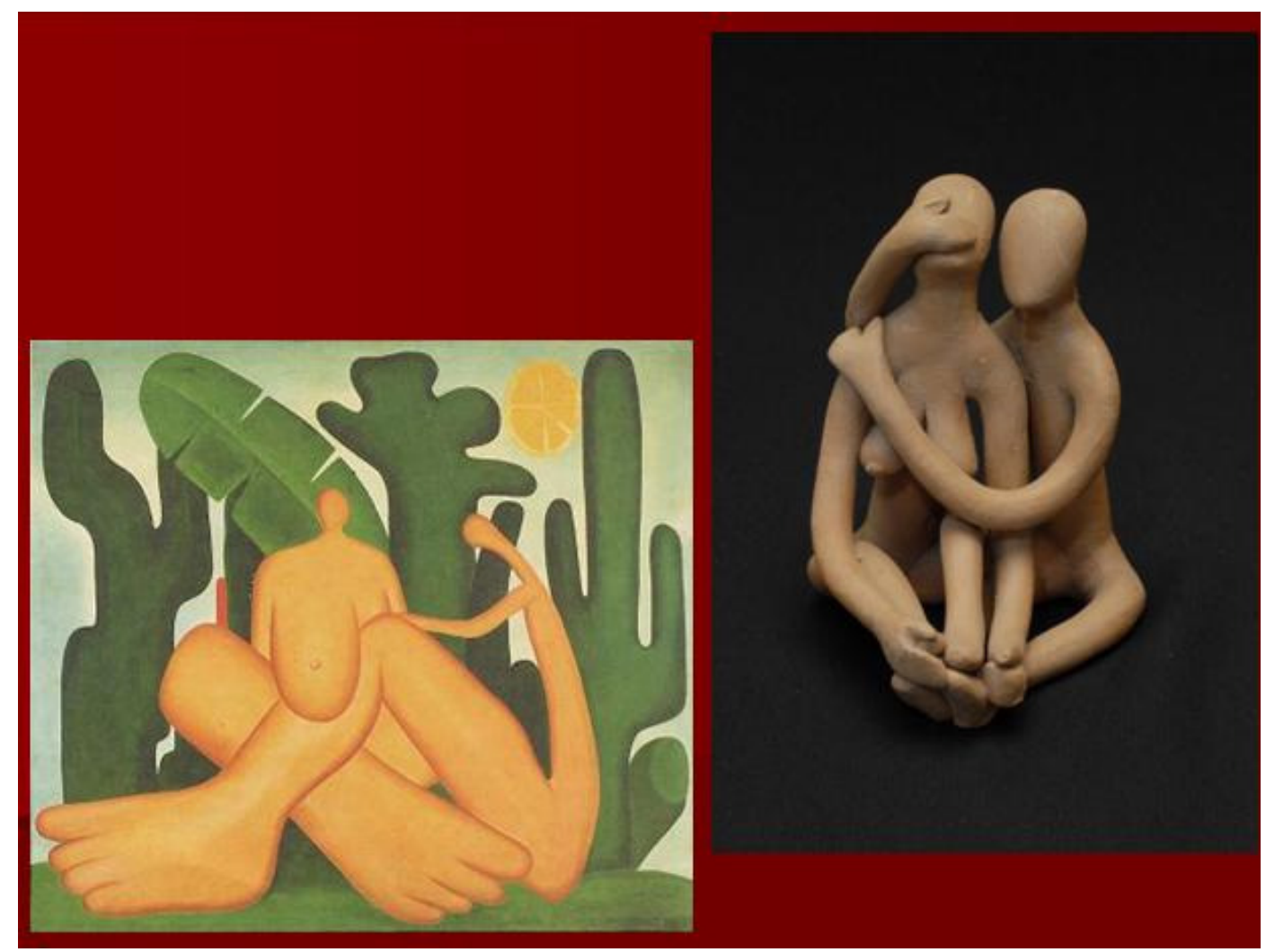

Si las miramos con detenimiento encontramos que en ambas la figura humana ocupa el centro, que en ambas el efecto de sentido se localiza en la fuerza de los cuerpos fusionados eróticamente en su gestualidad; en ambas lo que nos atrapa es la plasticidad de las formas, la armonía en el movimiento, la atmósfera que instalan. Hay también diferencias, más allá de los materiales y las técnicas; en la tela, la naturaleza es significante de la localización espacial; en la estatuilla sólo pueden primar la figura y su definición corporal, la armonía de la forma, el estallido de su sensualidad que se basta a sí misma para hacer posible la construcción del sentido. Esta figura es también la fuerza escultórica de un pequeño tallado en piedra de similar contenido:

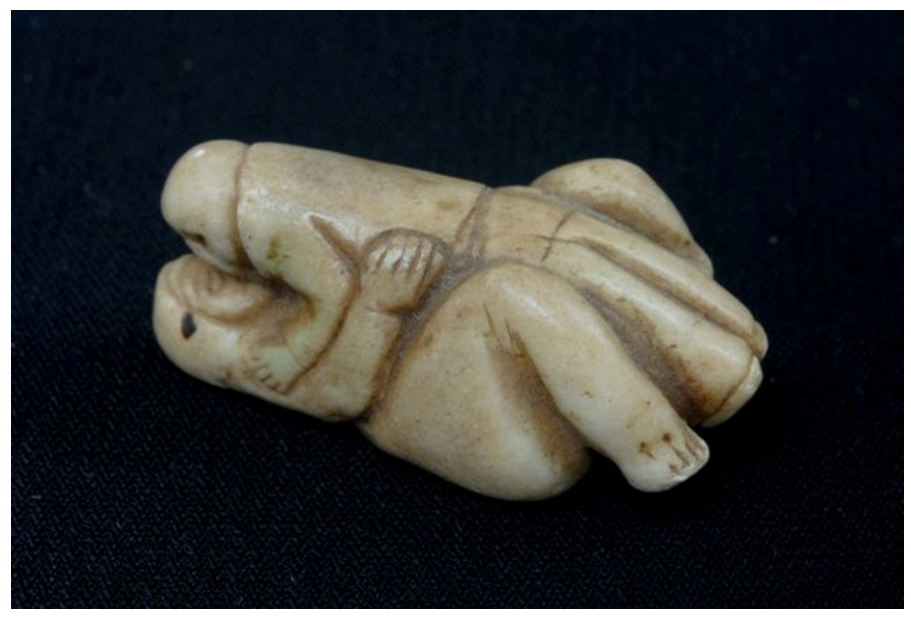


Ante mis ojos - e imagino que para la mayoría de los que las contemplan - estas imágenes apelan a la sensibilidad con intensidad pareja; si el efecto que producen es éste, entonces, ¿qué es lo que hace que la tela sea considerada "obra de arte", se exhiba en los museos internacionales y sea exponente del arte latinoamericano, en tanto que la estatuilla y la talla sean sólo expresiones "artesanales" de la misma cultura y sean mostradas sólo en un museo "local" para un público reducido?

Otro tanto ocurre cuando escuchamos (o leemos) unas líneas echadas al viento, dedicadas a "las madres de todos los días", escritas por el Indio Calco, un wichí de nuestro $\mathrm{Chaco}^{2}$, con las pocas letras aprendidas en su corta escolaridad:

Para. ti. hechura. Wiyento, AGUA. linda. mujer.

Cada. día. te. elijo.

y. esta. es. mi. Libertad. total. y. fuerte.

mi. abrazo. cumPle. Su. Elección. y. yo.

en. tu. Piel. que. se. teje. con. La. mía.

cada. día. te. veo. entre. los. hombres.

te. descubro. y. prefiero.

hechura. de. violenta. dulcedumbre.

amor. abierto. sobre. los. amores.

Se. desPuebla. la. tierra. si. te. pierdo.

Páramo. hundido. tórnanse. los. rostros

si. no. arde. el. tuyo.

y. toda. soledad. vuelve. a. agitar.

te. elijo. cada. día.

dentro. de. la. multitud. temblor.

En. diluvio. de. brazos. y. de. Pechos.

huyo. talando. Lebantadas. voses.

y. llego. a. tu. contorno. y. a. tu. fábula.

Sin. ti. se. desvanece.

La. Semejanza. humana. aguardame.

Perdura: te. elijo. Siempre. a. ti.

Y. esta. es. mi. libertad. ya. descarnada.

Quedémonos con el efecto que produce esta singular expresión de sentimientos y detengámonos en sólo algunas palabras: "mi abrazo cumple su elección y yo / en tu piel que se teje con la mía". Tengo para mí que acá el tejido construye una metáfora afincada en la vida de todos los días; que su valor poético radica, precisamente, en que el tejido es una forma de producción material insustituible, cuya práctica involucra a todos y de la que todos tienen conocimiento. La piel de los amantes se entrama en una malla de enorme resistencia, del mismo modo que los tejidos armados con manos endurecidas por el roce con el chaguar en ese mismo Chaco.

De esa práctica también da cuenta la imagen plástica como lo testimonia Litania Prado $^{3}$ en una serie de acuarelas y acrílicos fácilmente comparables con el llamado en occidente arte ingénuo:

\footnotetext{
${ }^{2}$ Texto reproducido por Fernanda Sola González (2006, p. 92). Acá se respeta la grafía del manuscrito cuyo autor nació alrededor de 1940 en la costa del Río Bermejo. En el año 1996, fecha en la que se toma este texto, residía en Finca La Morena, Hickman (Salta).

${ }^{3}$ Pieza perteneciente al Museo Pajcha, Salta.
} 


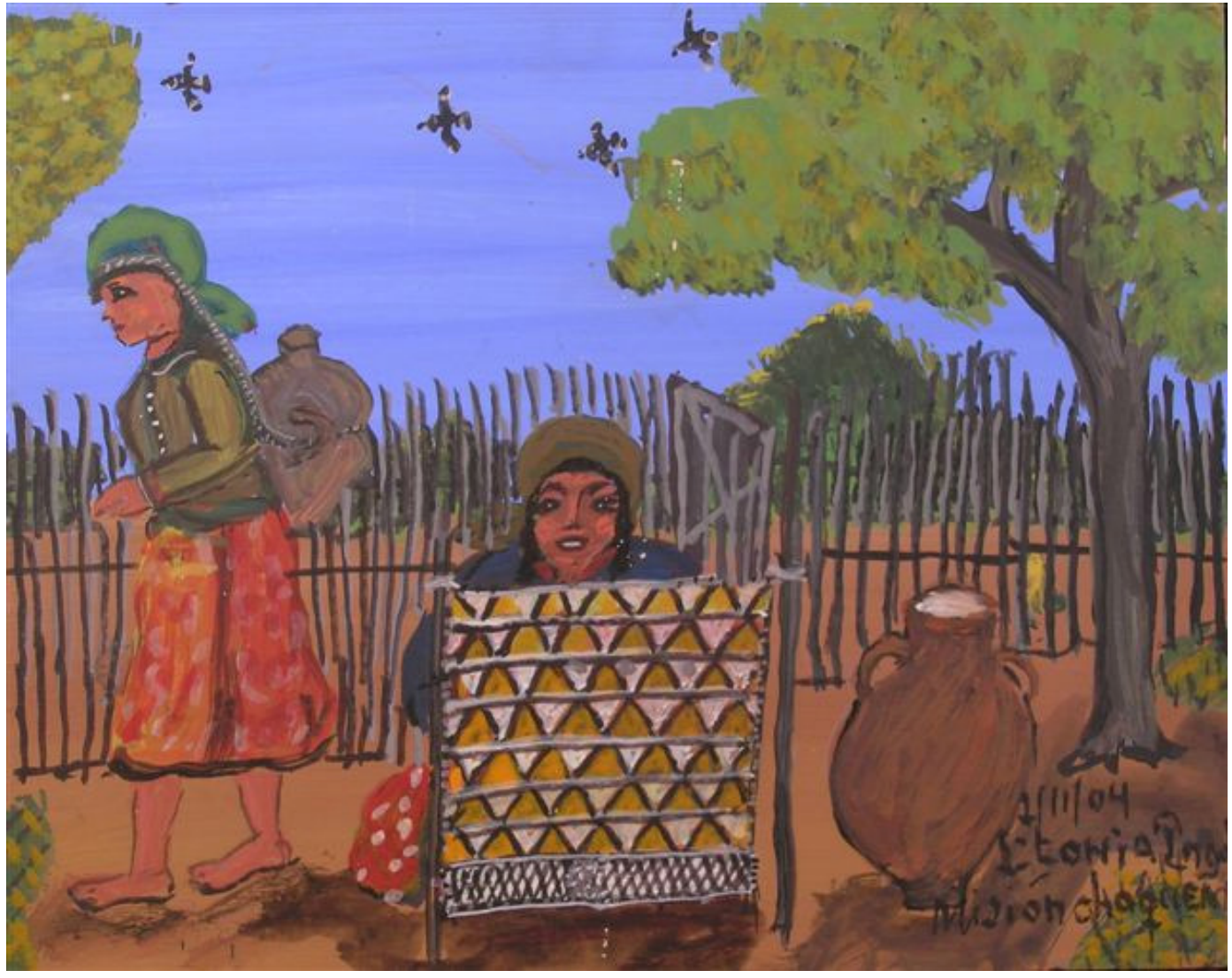

Es la nobleza del chaguar minuciosamente elaborado la que da vida a yiscas, fajas, cintos, tapices, objetos ornamentales, narrando una historia que va de los usos necesarios para la vestimenta y la manipulación doméstica hasta transformarse en objetos decorativos, generando una estetización destinada a un mercado más abierto: el de las "artesanías":

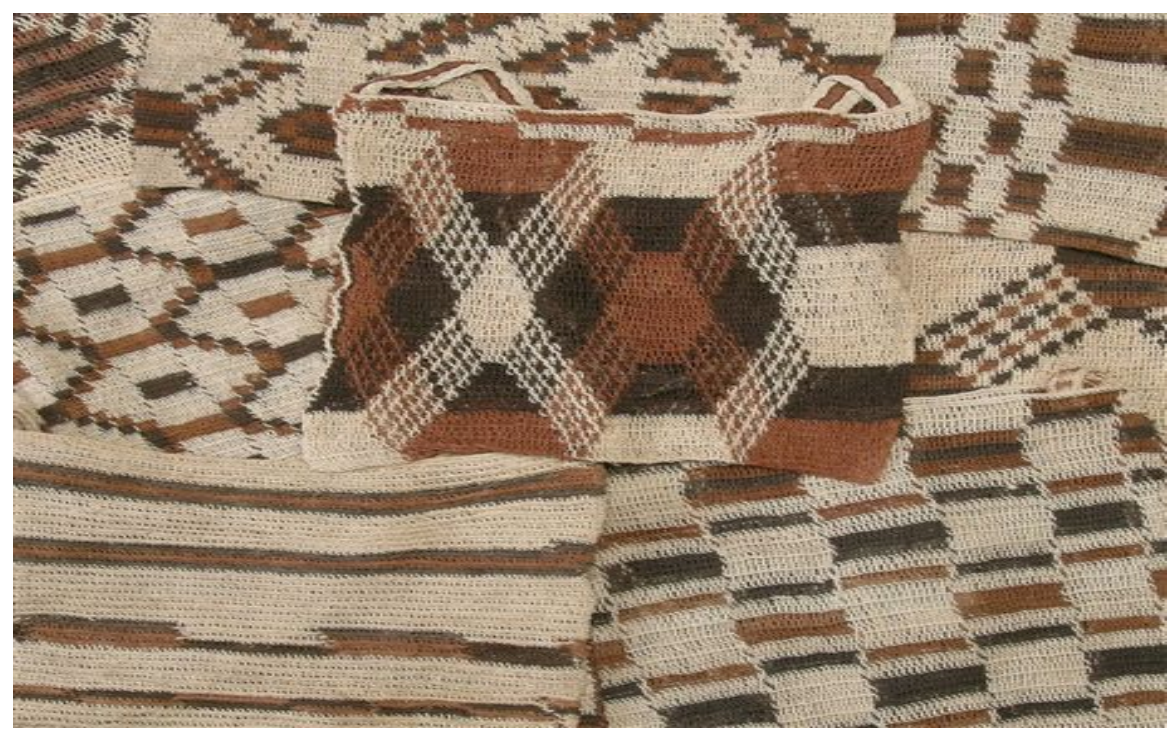




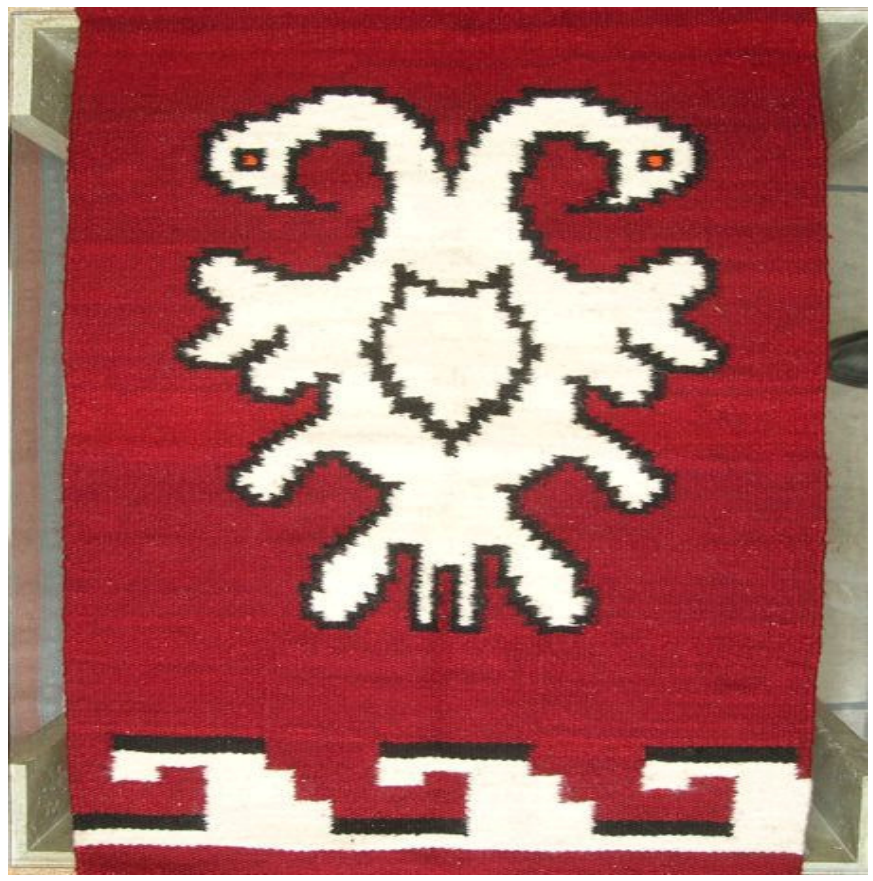

Conjunto de tejidos con figuras geométricas ${ }^{4}$.

El valor cultural que todos estos objetos invisten, sin embargo, va más allá de su funcionalidad desde el momento en que reinscriben en sus diseños motivos provenientes de la larga memoria comunal, en estrecha relación con el mundo animalístico y de la naturaleza.

Más extendido y transculturado - posiblemente porque esas comunidades fueron visualizadas con antelación y más rápidamente adaptadas a las exigencias de nuestra cultura - es el mundo textil de los valles calchaquíes o de la puna, por el rústico hilado de la lana proveniente de los camélidos propios de esas tierras ${ }^{5}$.

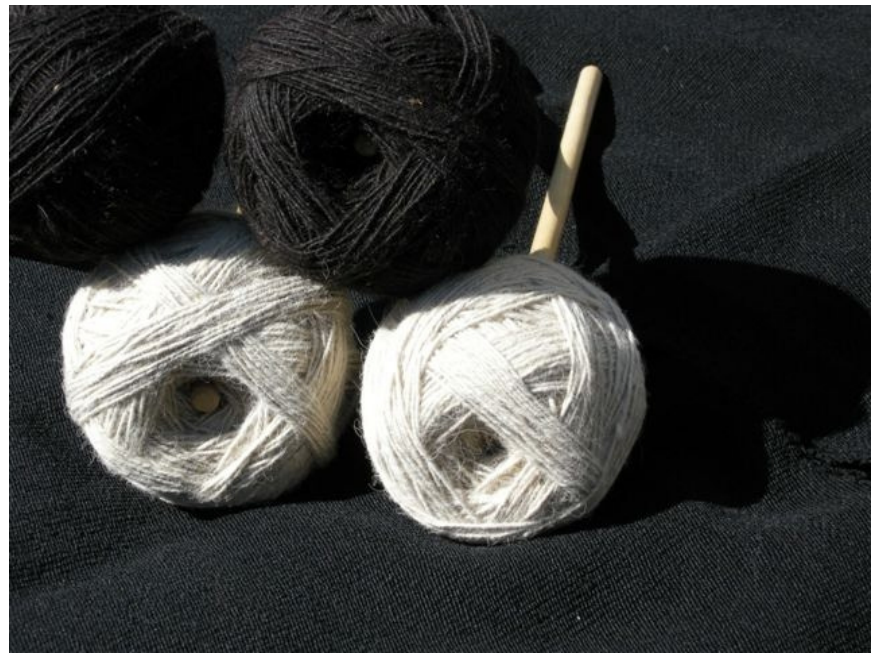

\footnotetext{
${ }^{4}$ Piezas pertenecientes al Museo Pajcha, Salta.

${ }^{5}$ Piezas pertenecientes al Museo Pajcha, Salta.
} 
Es el telar acá la tecnología por antonomasia después de la esquila, el hilado en el huso, el tinte y la elección del diseño. El vestido de llamas, vicuñas y ovejas se constituye, gracias a este arte, en protección, abrigo y utensilio de las comunidades ${ }^{6}$ :
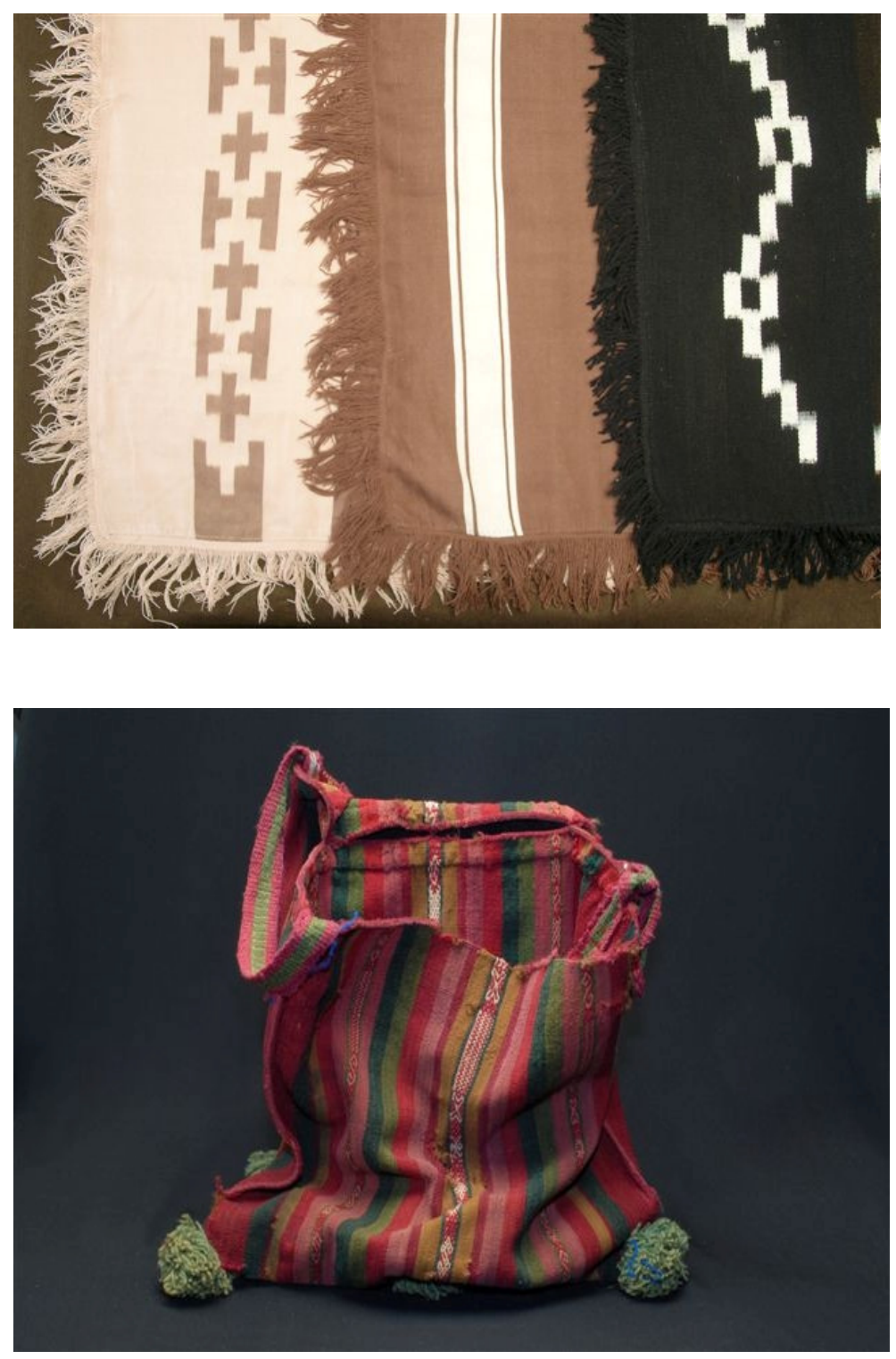

Artefactos textiles.

Y es tambien acá el paso del uso a la pura función decorativa, con marcada apropiación por los "artistas" exteriores a las comunidades el valor que subyace a una práctica que sigue siendo desvalorizada.

Con estas imágenes incorporadas volvamos a interrogarnos: ¿para cuántos de los que integraos el "campo cultural" latinoamericano estas imágenes y estas producciones tienen igual valor estético entre sí y entre ellas y las reconocidas como obras de arte?

\footnotetext{
${ }^{6}$ Piezas pertenecientes al Museo Pajcha, Salta.
} 
¿Desde dónde mirar estas formas de expresión, sin duda de significativa fuerza simbólica pero que no responden totalmente al "canon occidental”? ¿Pueden ser, por lo tanto, validadas e incorporarse a las historias del arte "universal"? En suma, ¿qué es el arte, qué la poièsis aquí, en América Latina, en Salta o La Quiaca, Chillán o Chiloé, Quito u Otavalo hoy, a comienzos del siglo XXI?

Una primera respuesta cae en lo obvio: es una forma de expresión centrada en la sensibilidad y que despierta efectos de sentido altamente heterogéneos. Las imágenes que miramos seguramente han producido efectos diversos en cada uno de nosotros, pero difícilmente las hayamos incorporado en lo que tenemos culturalmente naturalizado como expresiones artísticas. Y esto es así porque la historia del proceso civilizatorio trazó - desde el momento mismo de la conquista y colonización de las culturas de las que provienen estas producciones - una cartografía en la que las poéticas se definen desde un único lugar de producción y en función de las líneas de sus "valores estéticos", generando una diferencia hasta ahora insalvable entre culturas generadoras de cánones y culturas que sólo pueden ajustarse a ellos.

El concepto de "diferencia cultural" se concentra en el problema de la ambivalencia de la autoridad cultural: entre la tentativa de dominar, en nombre de una supremacía, las culturas "otras" y la alteridad construida dentro de la misma cultura por la heterogeneidad interior al sistema hegemónico. Al optar por la segunda alternativa, se opera en el espacio de la contradicción, entendida como el lugar de producción de sentido, en el que ya no se hace posible la afirmación de valores de verdad absoluta o de estructuraciones jerárquicas, sino de instancias en las que se localiza la conflictividad del pensamiento y el sentimiento de la diferencia.

Desde esta perspectiva se pone en duda, fundamentalmente, el principio de identidad sustentado por un discurso único e irrevocable, homogeneización sostenida a través de símbolos e íconos culturales condensadores de los principios que sustentan. Estas estrategias impiden mirar más allá de las emblematizaciones, a la vez que limitan la explicación y comprensión de las producciones culturales a simples relaciones de oposición.

Para salir de esta coyuntura propongo partir desde dentro mismo de la búsqueda del des-prendimiento de ese paradigma y, para ello, operar positivizando el pensamiento de la negatividad desde la que se construye la noción de "diferencia". Porque el arte es también, como sostiene Aníbal Quijano $(2001)^{7}$, la forma por antonomasia a través de la que los "vencidos" han resistido desde la colonia la imposición de ese paradigma, expresando a través de él la propia experiencia ya que:

En breve, los dominados aprendieron, primero, a dar significado y sentido nuevo a los símbolos e imágenes ajenos y después a transformarlos y subvertirlos por la inclusión de los suyos propios en cuanto imagen o rito o patrón expresivo de ajeno origen. No era posible, finalmente, practicar los patrones impuestos sin subvertirlos, ni apropiárselos sin reorganizarlos. Eso hicieron (QUIJANO, 2001, p. 125).

Se hace necesario, entonces, poner en circulación las múltiples formas de producción simbólica de las culturas "colonizadas", generando otros "lugares" desde donde "mirar" (en tanto es el "campo" que construye los cánones) desde hermenéuticas

\footnotetext{
${ }^{7}$ Existe un importante desarrollo acerca de la cuestión del arte y la escritura latinoamericanos; sólo señalo algunos de los más directamente vinculados con el lugar de enunciación acá sostenido: BÁMBULA DÍAZ (1992), MIGNOLO (1995 y 1998), QUIJANO (2001), ROIG (2003) y PALERMO (2009).
} 
pluritópicas (PALERMO, 2004). Y esos "lugares otros" se conforman des-aprendiendo lo que conocemos para abrir espacio a formas de valoración que pongan en simetría las producciones que siguen siendo consideradas "artesanales" con las de la "alta cultura". Es, en nuestro tiempo, generar la imprescindible simbiosis en la que aquellas expresiones ocupen el lugar que se les ha venido negando. De este modo queremos aproximar una perspectiva crítica, en el deseo de colaborar en la constitución de un campo cultural donde se privilegie la articulación entre sociedad y producciones simbólicas de carácter artístico atendiendo a las condiciones de producción de políticas que actúan por fuera de la "herencia colonial".

Ocupar ese lugar implica, también, en tiempos de globalización del aparato de mercado, aceptar que la obra de arte es una mercancía - para los estratos de gran poder adquisitivo se trata de adquirir una obra como "inversión" sin riesgo del mismo modo que el oro y más segura que las acciones bursátiles - tanto como lo es para ciertos sectores empresariales la mediación o incluso apropiación de la producción artesanal.

En efecto: si dejamos de lado las especulaciones relacionadas con la definición del arte en su relación con la artesanía y nos localizamos en el valor económico y en el movimiento comercial fuertemente incentivado por la producción internacionalizada del turismo, quienes resultan encontrarse siempre en situación de inferioridad son los productores de los objetos "artesanales", sin acceso a las redes del mercado, sin alternativas para incorporarse autónomamente a sus exigencias ${ }^{8}$.

Ello no implica que el ingreso al mercado lleve a una trivialización de la cultura y de sus valores simbólicos por la copia de un kitsch globalizado y muchas veces fomentado por los llamados microemprendimientos - entre los que no quedan fuera los del tipo "comercio justo" - validados por políticas públicas a veces honestamente convencidas de que sus apoyos favorecen el crecimiento de las comunidades (CONCHA, FIGUEIRA y PEDROSA, 2010). Por el contrario, se trata de la imprescindible necesidad de comprender y dimensionar lo que auténticamente las culturas ofrecen, práctica que creemos sólo puede alcanzarse desde su interioridad, por la generación de políticas sustentadoras de la autoestima de sus patrimonios que siguen manifestándose en fragmentos simbólicos volcados en objetos materiales, en relatos, canciones, danzas y usos culinarios plenos de sentido.

$\mathrm{Si}$ - como lo entendió Mariátegui - el auténtico "pueblo" de América Latina son las comunidades originarias (y nosotros agregamos las de afrodescendientes) en muchos casos devenidas en criollos en los espacios rurales y en "villeros" en los urbanos, es su cultura la que cimentará un auténtico proceso de afirmación de su identidad múltiple, heterogénea, contradictoria. De otro modo, si esa cultura popular se asimila a la masificación anómala y hegemonizante incentivada por los medios y por la circulación económica de la industria cultural como mercancía vaciada de sentido, no habrá posibilidad de que nuestros pueblos se construyan en sus diferencias y formen parte de la humanidad. manifiesta:

Sostengamos, en cambio, la convicción que mueve a J. B. Díaz cuando

La vitalidad de la cultura latinoamericana se encuentra, sin embargo, lejos de ser quebrantada y existen grandes posibilidades para que ella se convierta,

\footnotetext{
${ }^{8}$ Refiero acá en particular a la Argentina pues en otros estados andinos, como Colombia y crecientemente en Bolivia - en alguna medida también la nación mapuche en el sur de Chile - ocupan otros espacios en la redes internacionales.
} 
para el siglo XXI, en un epicentro de nuevas formas y tendencias expresivas y de un nuevo papel de lo estético dentro del contexto cultural general del mundo [...] En este sentido podemos suponer que la situación estéticocultural de América Latina, con tal que se logre construir espacios alternativos de resistencia al embate de la cultura comercial de masas, constituye una ventaja y un punto de partida muy fructífero para futuros procesos culturales de carácter universal (BÁMBULA DÍAZ, 1993, p. 178179).

\section{BIBLIOGRAFIA}

CONCHA, P.; FIGUEIRA, P; y PEDROSA, M. Ni comercio, ni ayuda: pensando la reexistencia. Informe Final subsidio Fondo Nacional de las Artes (Argentina), 2010 (inédito).

BÁMBULA DÍAZ, Jùliene. La estética en la dinámica de la cultura. Cali: Universidad del Valle, 1993.

MIGNOLO, Walter. The Darker Side of the Renaissence: Literacy, Territoriality \& Colonization. Michigan: Ann Arbor, 1995.

p. 171-188.

Diferencia colonial y razón posoccidental. Anuario Mariateguiano. V. X, n. 10,

PALERMO, Zulma. Comparatismo contrastivo y hermenéuticas pluritópicas: variaciones latinoamericanas. Actas del Congreso "Espacios y discursos compartidos en la literatura latinoamericana". Lima: Fondo Editorial de la UCSS, 2004. p. 319-332.

. (Coordenación). Arte y estética en la encrucijada descolonial. Cuad. $n^{\circ} 6$ de la Colección El desprendimiento: pensamiento crítico y opción descolonial. Coord. Walter Mignolo. Buenos Aires: Ed. del Signo, 2009.

QUIJANO, Aníbal. Colonialidad del poder, globalización y democracia. In: Tendencias basicas de nuestra era. Caracas: Instituto de Altos Estudios Internacionales. Reproducido en Trayectorias (Revista de CCSS). Méjico: Universidad Autónoma de Nuevo León, Méjico. Año 4, n. 7/8, setiembre 2001-2002, p. 58-91.

ROIG, Arturo. Arte impuro y lenguaje: bases teóricas e históricas para una estética motivacional. Universum, $\mathrm{n}^{\circ}$. 18, p. 173-192.

SOLA GONZÁLEZ, Fernanda. Artesanías de Salta: herencia viva. Salta: Secretaría de Cultura de la Provincia de Salta, 2006. 